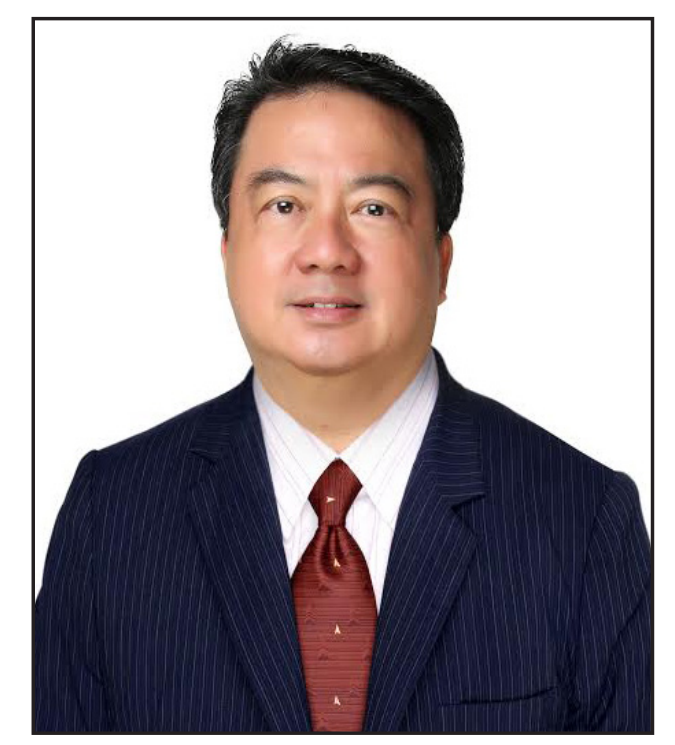

\title{
One in Research as One PSO-HNS
}

Research is the tool that unravels what people have seen and ponder on ideas which nobody else has thought. As Neil Armstrong stated, Research is creating new knowledge. This percipience ignites development of every individual.

For this reason, the Philippine Society of Otolaryngology - Head and Neck Surgery (PSO-HNS) is committed to its objective of contributing insights and skills in the diagnosis and treatment of ENT-Head and Neck ailments. Fellows Research Grants are available to augment the expenses incurred during the process.

The various research contests hosted by the society through the commendable efforts and passion of our Vice-President and concurrent Scientific Chair Dr. Erasmo Gonzalo D. V. Llanes will continue to be the source of academic writings for the internationally recognized Philippine Journal of Otolaryngology Head and Neck Surgery (PJOHNS).

Our society recognizes the wisdom and leadership of the PJOHNS Editor-in-Chief Dr. Jose Florencio F. Lapeña, Jr. in maintaining the international stature of our publication.

However, the task should be a collaborative effort of everyone and not limited to our training institutions.

We should be One in Research as One PSO-HNS!

Mabuhay ang PJOHNS!

DANILO A. POBLETE, MD, FPSOHNS 